\title{
Morphometric documentation of abnormal intramyocellular fat storage and reduced glycogen in obese patients with Type II diabetes
}

\author{
K. Levin ${ }^{1}$, H.Daa Schroeder ${ }^{2}$, F. P. Alford ${ }^{3}$, H. Beck-Nielsen ${ }^{1}$ \\ ${ }^{1}$ Diabetes Research Centre, Department of Endocrinology M and ${ }^{2}$ Department of Pathology, Odense University Hospital, \\ Odense, Denmark \\ ${ }^{3}$ Department of Endocrinology and Diabetes, St. Vincent Hospital, Fitzroy, Melbourne, Victoria, Australia
}

\section{Abstract}

Aims/hypothesis. Insulin resistance of skeletal muscle has been associated with increased lipid availability. This study aimed to estimate volume fractions of intramyocellular triglyceride droplets and glycogen granules in skeletal muscle using electron microscopy and furthermore, relate these findings to insulin sensitivity and the level of circulating lipids.

Methods. We compared 11 obese patients with Type II (non-insulin-dependent) diabetes mellitus and 11 obese normoglycaemic subjects matched for age and sex. Glucose metabolism was determined using the euglycaemic hyperinsulinaemic clamp technique $\left(40 \mathrm{mU} \cdot \mathrm{m}^{-2} \cdot \mathrm{min}^{-1}\right)$ coupled with indirect calorimetry and tritiated glucose. On the second day, using an automatic procedure, a fasting muscle biopsy was carried out and processed for electron microscopy. Volume fractions of intramyocellular structures were estimated by pointcounting on photographic pictures in a blinded manner.

Results. Insulin-stimulated total glucose disposal rate was lower in the Type II diabetic subjects compared with the obese normoglycaemic subjects $(4.96 \pm 049$ vs $\left.10.35 \pm 0.89 \mathrm{mg} \cdot \mathrm{min}^{-1} \cdot \mathrm{kg} \mathrm{ffm}^{-1}, p<0.001\right)$ as was glucose storage $(2.03 \pm 0.50$ vs $6.59 \pm 0.83, p<0.001)$. The electron microscopy study revealed that the diabetic subjects had higher intramyocellular amounts of triglyceride $(1.43 \pm 0.21$ vs $0.39 \pm 0.07 \%, p<$ $0.001)$ and lower amounts of glycogen $(3.53 \pm 0.33 \mathrm{vs}$ $6.94 \pm 0.54 \%, p<0.001)$. Mitochondrial volume was identical indicating equal aerobic capacity. The fractional intramyocellular lipid volume was found to be positively associated with fasting NEFA $(r=0.63$, $p=<0.05$ and $r=0.79, p=<0.05)$ and triglyceride $(r=0.74, p=0.01$ and $r=0.62, p<0.05)$ in the obese diabetic and normoglycaemic cohorts respectively. Intramyocellular lipid content was negatively correlated to insulin sensitivity $(r=-0.71, p<0.02)$ in the obese diabetic group whereas no significant association was found in the obese normoglycaemic group. Conclusion/interpretation. This study shows that fat accumulates intramyocellulary while glycogen stores are simultaneously reduced in obese subjects with Type II (non-insulin-dependent) diabetes mellitus. Quantitatively, a major component of the excessive lipid accumulation could be secondary in origin, related to the diabetic state in itself, although a contribution from the altered insulin action cascade of obesity and diabetes cannot be excluded. In both groups significant positive relations were found between circulating and intramyocellular lipid. [Diabetologia (2001) 44: 824-833]

Keywords Type II diabetes, insulin sensitivity, skeletal muscle, intramyocellular, electron microscopy, triglyceride, glycogen
Received: 6 December 2000 and in revised form: 16 March 2001

Corresponding author: K. Levin, MD, Department of Endocrinology M, Kloevervaenget 6, 1, Odense University Hospital, DK-5000 Odense C, Denmark

Abbreviations: FFM, Fat free mass; NMR, nuclear magnetic resonance; cpm, counts per minute; $\mathrm{Rd}$, total glucose disposal; GS, glucose storage; $\mathrm{Si}$, insulin sensitivity index
Over the last decade, the role of excessive lipid availability in the pathogenesis of Type II (non-insulin-dependent) diabetes mellitus has been the subject of increasing attention [1-4]. It has recently been suggested that the disease could be better characterized in terms of defects in fat metabolism with secondary changes in carbohydrate metabolism and in beta-cell 
secretory capacity [5]. An inverse relation exists between glucose and fat as metabolic fuels, with inappropriate increases (by infusion of lipid emulsion) in the supply of fatty acids, leading to an impairment of glucose utilization and a reduction in insulin sensitivity, whereas insulin sensitivity improves if the NEFA metabolism is modified pharmacologically [6-12].

Skeletal muscle is generally believed to be important for the removal of NEFA from the circulation $[2,13]$, and it usually contains substantial amounts of stored triglyceride that provide an efficient energy source for muscles. Obese subjects with Type II diabetes have an increased rate of NEFA turnover per unit of skeletal muscle mass, in addition to being insulin resistant $[2,14]$. Although it is difficult to disentangle cause and effect, an excess accumulation of triglyceride in skeletal muscle could play a primary pathophysiological role in the causation of the reduced insulin sensitivity. Thus, in a group of obese Pima Indians with normal glucose tolerance investigators found muscle triglyceride to be closely related to the degree of insulin resistance [15]. Other investigators using a semiquantitative histological method were able to demonstrate a negative association between glycogen synthase activity and intracellular lipid in a population of normoglycaemic obese women [16]. Recently, the nuclear magnetic resonance (NMR) spectroscopy technique has been used to determine muscle lipid content and showed that intramyocellular lipid concentrations was inversely correlated to insulin sensitivity in a group of normal weight non-diabetic subjects and in relatives of subjects with Type II diabetes [17-20]. The NMR studies have been conducted on net cross-sections of muscle, whereas the current study uses quantitative electron microscopy to investigate anatomically the intramyocellular space.

This study, therefore, used electron microscopy EM to estimate the intramyocellular volume of triglyceride in skeletal muscle of obese Type II diabetic subjects and matched obese normoglycaemic subjects. We related these findings to insulin sensitivity as determined by the euglycaemic hyperinsulinaemic clamp method. The EM technique offers the additional advantage of a simultaneous quantification of the intramyocellular glycogen content and the assessment of mitochondria, as well as the localisation and morphology intramyocellulary of these organelles and substrates.

\section{Subjects and methods}

Subjects. A total of 11 subjects with Type II diabetes and 11 obese subjects with no family history of diabetes were recruited for the study. All were Caucasians and followed a sedentary lifestyle. The obese subjects were matched for age, sex and body mass index and all had a normal glucose tolerance, as as- sessed by an oral glucose tolerance test. Of the subjects with Type II diabetes, two were on sulfonylurea therapy, five were on metformin therapy and four were on diet therapy alone. Altogether five of the diabetic subjects and two of the obese normoglycaemic subjects were being treated for hypertension. All anti-diabetic medication had been discontinued 3 weeks before the start of the metabolic studies. During this period mean fasting plasma glucose concentrations increased from $9.8 \pm 1.2$ to $12.3 \pm 1.3 \mathrm{mmol} / \mathrm{l}$, subjects were asymptomatic and weight did not change. None of the participants suffered from a major disease other than diabetes and hypertension as assessed by clinical investigation and standard laboratory examinations. Subjects were instructed not to change their diet and amount of physical activity during the study and to avoid excessive physical exercise at least 3 days before all metabolic investigations. Informed written consent was obtained from all subjects after the purpose and potential risks of the study were explained to them. The study was approved by the regional ethical committee and was in accordance with the Helsinki declaration.

Study protocol. All studies began at 0800 hours after a 10- to 12$\mathrm{h}$ overnight fast. The design of the study in which subjects were examined three times is illustrated graphically on Figure 1.

Euglycaemic hyperinsulinaemic clamp. The diabetic subjects were admitted to the clinical research centre the evening before the start of the study in order to induce euglycaemic steady state (about $5.2 \mathrm{mmol} / \mathrm{l}$ ) by a variable infusion of insulin using an antecubital vein catheter. Blood samples for plasma glucose analyses were drawn from a catheter inserted into a dorsal wrist vein of the opposite arm. The obese normoglycaemic subjects were admitted to the centre at 0800 hours at which time intravenous catheters were inserted. During the study the subjects remained in a supine position with the hand designated for collection of blood samples placed and maintained in a heated Plexiglas box for arterialization of venous blood [21]. After a 30-min relaxation period, at time zero, a surface adjusted priming dose of $3-{ }^{3} \mathrm{H}$ glucose was given $\left(14 \mu \mathrm{Ci} / \mathrm{m}^{2}\right)(\mathrm{Du}-$ Pont-New England Nuclear, Boston, Mass., USA), followed by a continuous infusion of $3-{ }^{3} \mathrm{H}$ glucose $\left(0.14 \mu \mathrm{Ci} \cdot \mathrm{min}^{-1}\right.$. $\mathrm{m}^{2(-1)}$, which was continued throughout the study periods. After a 120 -min basal tracer equilibration period, insulin (Actrapid, Novo-Nordisk, Bagsvaerd, Denmark) was infused at a rate of $40 \mathrm{mU} \cdot \mathrm{min}^{-2} \cdot \mathrm{min}^{-1}$ for $180 \mathrm{~min}$ and euglycaemia maintained using a variable infusion of $18 \%$ glucose. To keep plasma specific activity constant at the basal level during the clamp, $3-{ }^{3} \mathrm{H}$ glucose was added to the glucose infusate (HOTGINF) as previously described [22]. Steady-state periods were defined as the last $30 \mathrm{~min}$ during basal and insulin stimulated measurements, respectively.

Glucose and lipid oxidation. Indirect calorimetry was done using a computerized flow through canopy gas analyser system (Deltatrac, Datex, Helsinki, Finland) as previously described [10]. After an equilibration period of $10 \mathrm{~min}$, the average gas exchanges recorded over the two 30 -min steady state periods were used to calculate rates of glucose oxidation, lipid oxidation and energy expenditure [23]. The protein oxidation rate was estimated from urinary urea nitrogen excretion $(1 \mathrm{~g}$ of nitrogen $=6.25 \mathrm{~g}$ of protein) and corrected for changes in pool size [24].

Calculations. Rates of total glucose appearance ( $\mathrm{Ra}$ ) and glucose disposal ( $\mathrm{Rd})$, were calculated from the plasma concentrations of tritiated glucose and plasma glucose using Steele's non-steady-state equations [25]. In these calculations, the dis- 
Diabetic subjects

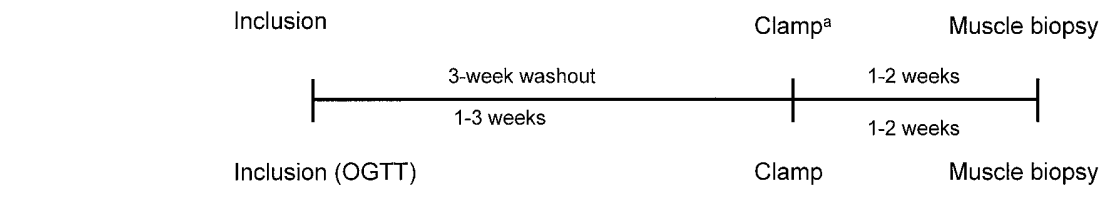

Normoglycaemic

obese subjects

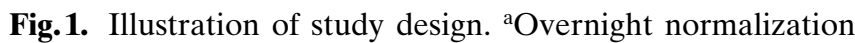
of plasma glucose

tribution volume of glucose was taken as $200 \mathrm{ml} / \mathrm{kg}$ body weight and the pool fraction as 0.65 . Hepatic glucose output was calculated as the difference between $\mathrm{Ra}$ and the glucose infusion rate (GINF). During the basal equilibration period plasma glucose specific activity $\left(\mathrm{cpm} \cdot \mathrm{mg}^{-1}\right.$ glucose) was $788.3 \pm 41.9$ at $20 \mathrm{~min}$ and $776.4 \pm 45.9$ after $120 \mathrm{~min}$ in the diabetic group and $806.0 \pm 28.1$ and $834.3 \pm$ in the obese normoglycaemic group confirming steady state. Specific activities at the end of the second pre-defined steady state period were $897.3 \pm 59.4$ and $824.3 \pm 36.9$ in the two groups respectively. The in vivo glycolytic flux rates were calculated from the rates of generation of plasma ${ }^{3} \mathrm{H}_{2} \mathrm{O}$ from $3{ }^{3} \mathrm{H}$ glucose as previously described [26, 27]. Briefly, this measurement is based on the observation that essentially all of tritium in the $\mathrm{C}-3$ position is lost to water at the triose-isomerase reaction during the glycolytic process. Thus, the glycolytic flux rate can be calculated by multiplying the slope of the regression line obtained from the plot between time and ${ }^{3} \mathrm{H}_{2} \mathrm{O}$ content $\left(\mathrm{cpm} \cdot \mathrm{ml}^{-1} \cdot \mathrm{min}^{-1}\right)$ with total body water $(\mathrm{ml})$ estimated from the bioimpedance measurement and divided by plasma specific activity (cpm/ $\mathrm{mg}$ ). In these calculations, plasma water was assumed to be $93 \%$ of the total plasma volume [27]. Linearity of the accumulation of plasma tritiated water radioactivity was obtained from -100 to $0 \mathrm{~min}$ during basal measurements $(r=0.94 \pm 0.01$ and $r=0.94 \pm 0.02)$ and from 40 to $180 \mathrm{~min}$ during insulin infusion $(r=0.96 \pm 0.01$ and $r=0.97 \pm 0.01)$ in the obese diabetic and obese normoglycaemic group, respectively.

Rates of glucose storage (GS) were calculated as the difference between Rd and glycolytic flux. Non-oxidative glucose disposal as the difference between $\mathrm{Rd}$ and glucose oxidation as determined by indirect calorimetry. The insulin sensitivity indices of $\mathrm{Rd}$ and GS which mainly represent skeletal muscle glucose processing were expressed as the glucose metabolic parameter per increment in plasma insulin induced by the hyperinsulinaemic clamp compared with baseline values, standardized to the plateau clamp glucose concentration, as described in a study from our laboratory [26, 28, 29]. Body composition was estimated with the bioimpedance method using the formula of Lukaski [30]. All data of glucose metabolism are given as $\mathrm{mg} \cdot \mathrm{min}^{-1} \cdot \mathrm{kg} \mathrm{ffm}{ }^{-1}$.

Muscle biopsy. As the induction of euglycaemia by an overnight insulin infusion could influence muscle substrate volumes at least theoretically, we deliberately chose (in both groups) to obtain the muscle biopsies on a second day in order to reflect habitual fasting conditions [31]. Thus, a percutaneous muscle biopsy (about 20-30 mg) was taken under local anaesthesia ( $2 \%$ lidocaine without epinephrine) from musculus vastus lateralis of the leg $20 \mathrm{~cm}$ above the knee using an automatic procedure (Pro-mag Automatic Biopsy System, Manan Medi- cal Products, Northbrook, Ill., USA). Biopsies were immediately fixed in buffered $2 \%$ glutaraldehyde. The tissue was cut in smaller pieces, postfixed in osmium tetroxid block stained with uranyl acetate and imbedded in Epon. Semithin sections were cut out from two blocks and technically well preserved areas were selected by the technician for ultrathin sections. Ultrathin sections were grid stained with lead citrate and analysed in a Philips EM208 electron microscope. For each subject 12 pictures were taken randomly for morphometric analysis. The morphometric analysis was performed on blinded material by one of the authors. Initially, counts were done on 12 pictures in 4 subjects. It was found, however, that from 5 pictures onwards, pictures gave rise to variation in estimates not surmounting $10 \%$ which is in accordance with previous stereological studies [32]. Consequently, 5 pictures were chosen for the rest of the subjects. Volume fractions of lipid, glycogen and mitochondria were estimated according to standard stereological principles by counting the points in a test system which hit the structure and dividing them by the total number of points hitting muscle fibers $[32,33]$. The final magnification was 14700 and the density of points was 2240 per micrograph.

Analytical procedures. Bedside plasma glucose (for adjustment of the variable glucose infusion during the clamp) was measured using a glucose oxidase method (Glucose Analyzer II, Beckmann Instruments, Fullerton, Calif, USA). Tritiated glucose activity was measured as previously described [22]. Plasma glucose was measured using a glucose dehydrogenase Method (Merck Diagnostica, Darmstadt, Germany) on an Axon-Technicon (Bayer-Diagnostics, München, Germany). Plasma insulin was analysed by a two-site, time-resolved immunofluorometric assay (DELFIA) [34]. Non-esterified fatty acids were measured by an enzymatic colorimetric method (Wako Chemicals GmbH, Neuss, Germany) as was triglyceride (Boehringer Mannheim - Diagnostica, Mannheim, Germany). Serum urea nitrogen was measured using an enzymatic method on an Technicon Axon (Technicon Instruments, Tarrytown, N. Y., USA). Urinary urea nitrogen was measured using an enzymatic method on a Cobas Mira S (Roche, Basle, Switzerland).

Statistical analysis. Differences in means between the groups or within groups were tested using unpaired or paired $t$-tests respectively (two-tailed). In the absence of normality, variables were logarithmically transformed to achieve normal distribution before statistical calculation. For correlation analysis Spearman's rho was employed. All analyses were performed with the SPSS computer programme, version 7.5 for Windows (SPSS, Chicago, Ill., USA). Data are presented as means \pm SE or means (95\%-Confidence intervals) unless otherwise stated. A $p$ value of less than 0.05 was considered significant. 
Table 1. Clinical characteristics of the study subjects

\begin{tabular}{|c|c|c|c|}
\hline Cohort & $\begin{array}{l}\text { Type II } \\
\text { diabetic } \\
\text { subjects }\end{array}$ & $\begin{array}{l}\text { Normogly- } \\
\text { caemic obese } \\
\text { subjects }\end{array}$ & $p$-value \\
\hline Number (f/m) & $11(1 / 10)$ & $11(2 / 9)$ & NS \\
\hline Age (years) & $52.3 \pm 1.7$ & $53.6 \pm 3.0$ & NS \\
\hline $\begin{array}{l}\text { Duration of diabetes } \\
\text { (years) }\end{array}$ & $3.3 \pm 0.8$ & & \\
\hline BMI $\left(\mathrm{kg} / \mathrm{m}^{2}\right)$ & $31.8 \pm 1.6$ & $31.4 \pm 1.4$ & NS \\
\hline Weight (kg) & $92.7 \pm 3.9$ & $95.7 \pm 4.2$ & NS \\
\hline FFM (kg) & $57.0 \pm 2.3$ & $51.9 \pm 2.4$ & NS \\
\hline FM (kg) & $35.7 \pm 4.9$ & $43.8 \pm 2.8$ & NS \\
\hline $\begin{array}{l}\text { Fasting plasma glucose } \\
(\mathrm{mmol} / \mathrm{l})\end{array}$ & $12.3 \pm 1.2$ & $5.6 \pm 0.1$ & $<0.001$ \\
\hline $\begin{array}{l}\text { Fasting plasma NEFA } \\
(\mathrm{mmol} / \mathrm{l})\end{array}$ & $0.65 \pm 0.07$ & $0.36 \pm 0.03$ & $<0.005$ \\
\hline $\begin{array}{l}\text { Fasting plasma insulin } \\
(\mathrm{pmol} / \mathrm{l})\end{array}$ & $\begin{array}{l}62.7 \\
(32.5-121.1)^{\mathrm{a}}\end{array}$ & $\begin{array}{l}46.8 \\
(34.3-64.1)^{\mathrm{a}}\end{array}$ & NS \\
\hline $\begin{array}{l}\text { Fasting plasma } \\
\text { triglyceride }(\mathrm{mmol} / \mathrm{l})\end{array}$ & $3.0(1.7-5.3)^{\mathrm{a}}$ & $1.1(1.1-1.5)^{\mathrm{a}}$ & $<0.005$ \\
\hline $\begin{array}{l}\text { Fasting serum cholesterol } \\
(\mathrm{mmol} / \mathrm{l})\end{array}$ & $6.3(5.4-7.3)^{\mathrm{a}}$ & $6.1(5.7-6.6)^{\mathrm{a}}$ & NS \\
\hline $\begin{array}{l}\text { Fasting serum HDL- } \\
\text { cholesterol }(\mathrm{mmol} / \mathrm{l})\end{array}$ & $1.1(0.8-1.1)^{\mathrm{a}}$ & $1.4(1.1-1.6)^{\mathrm{a}}$ & $<0.01$ \\
\hline
\end{tabular}

${ }^{\text {a }}$ Logarithmically transformed

\section{Results}

Clinical and fasting laboratory characteristics of the subjects are summarized in Table 1. Plasma glucose concentrations at the clamp study were similar in the diabetic and obese normoglycaemic subjects during both the basal $(5.8 \pm 0.2$ vs $5.9 \pm 0.1 \mathrm{mmol} / \mathrm{l}, \mathrm{NS})$ and insulin stimulated $(5.4 \pm 0.2$ vs $5.5 \pm 0.1 \mathrm{mmol} / \mathrm{l}$, NS $)$ steady state period. Because of the overnight normalization of plasma glucose, basal plasma insulin increased in the diabetic subjects $(182.3 \pm 28.9$ vs $43.1 \pm 5.6 \mathrm{pmol} / \mathrm{l}, p=0.001)$ but was more or less the same during insulin stimulation $(384.0 \pm 24.1$ vs
$369.1 \pm 20.7 \mathrm{pmol} / \mathrm{l}, p=\mathrm{NS})$. As noted for plasma glucose, overnight insulin infusion resulted in identical basal NEFA concentrations $(0.43 \pm 0.08$ vs $0.44 \pm 0.06 \mathrm{mmol} / \mathrm{l}, p=\mathrm{NS}$ ) whereas clamp procedures revealed a reduced suppression of NEFA in the diabetic group $(0.22 \pm 0.04$ vs $0.01 \pm 0.0 \mathrm{mmol} / \mathrm{l}$, $p<0.001)$.

During insulin stimulation, GINF, Rd, glucose oxidation, non-oxidative glucose metabolism, glycolytic flux and GS were significantly lower in the diabetic subjects. In contrast, lipid oxidation was significantly higher. All steady state rates of glucose and lipid metabolism are presented in Table 2. Resistance to the action of insulin was noted in the Type II diabetic subjects for $\mathrm{Si}_{\mathrm{RD}}$ and $\mathrm{Si}_{\mathrm{GS}}$ when these clamp metabolic data were expressed as rates of change per unit change in insulin, that is, insulin sensitivity indices (Table 2).

Morphometric analyses, electronmicroscopy. The ultrastructure of the muscle fibres appeared normal and there was no qualitative difference between Type II diabetic subjects and obese normoglycaemic subjects. Thus, in both groups, glycogen granules were found either in association with mitochondria or intermyofibrillary dispersed, which suggests that they could also be involved in anaerobic glycolysis $[35,36]$. Lipid vacuoles were found almost exclusively in close contact with mitochondria and appeared more prominent both in number and size in the diabetic subjects. Examples of electron microscopic fields with intramyocellular triglyceride are shown in Figure 2A and examples of electron microscopic fields with glycogen are shown in Figure 2B. The morphometric analysis demonstrated an approximately 3.7-fold higher intramyocellular volume fraction of lipids in the diabetic subjects $(1.43 \pm 0.21 \mathrm{vs}$ $0.39 \pm 0.07 \%, p<0.001)$ while the volume fraction occupied by glycogen granules was approximately 2 fold larger in the obese normoglycaemic subjects

Table 2. Rates of glucose and lipid metabolic parameters during clamp studies and insulin sensitivity indices for $\mathrm{Si}_{\mathrm{RD}}$ and $\mathrm{Si}_{\mathrm{GF}}$

\begin{tabular}{|c|c|c|c|c|}
\hline & \multicolumn{2}{|c|}{ Type II diabetic subjects } & \multicolumn{2}{|c|}{ Normoglycaemic obese subjects } \\
\hline & Basal & Insulin & Basal & Insulin \\
\hline \multicolumn{2}{|l|}{ Glucose infusion (GINF) } & $3.12(2.21-4-42)$ & & $8.43(7.06-10.1)^{\mathrm{d}}$ \\
\hline Hepatic glucose output & $3.66 \pm 0.24$ & $1.51 \pm 0.31^{\mathrm{b}}$ & $3.44 \pm 0.16$ & $1.70 \pm 0.27^{\mathrm{b}}$ \\
\hline Glucose oxidation & $2.23 \pm 0.21$ & $2.41 \pm 0.21$ & $2.41 \pm 0.41$ & $5.42 \pm 0.45^{\mathrm{b}, \mathrm{d}}$ \\
\hline Lipid oxidation & $1.59 \pm 0.19$ & $1.48 \pm 0.20$ & $1.53 \pm 0.23$ & $0.51 \pm 0.20^{\mathrm{b}, \mathrm{d}}$ \\
\hline Non-ox. glucose metab. & $1.55 \pm 0.22$ & $2.56 \pm 0.46^{\mathrm{a}}$ & $1.17 \pm 0.42$ & $4.93 \pm 0.74^{\mathrm{b}, \mathrm{c}}$ \\
\hline $\mathrm{Si}_{\mathrm{RD}}$ & & $4.31 \pm 2.19$ & & $22.35 \pm 3.22^{\mathrm{d}}$ \\
\hline $\mathrm{Si}_{\mathrm{GS}}$ & & $11.98 \pm 2.39$ & & $21.80 \pm 3.40^{\mathrm{c}}$ \\
\hline
\end{tabular}

Steady-state rates of metabolic parameters are expressed as $\mathrm{mg} \cdot \mathrm{min}^{-1} \cdot \mathrm{kg} \mathrm{ffm}^{-1}$

Indices of insulin sensitivity are expressed as $\mu \mathrm{l} \cdot \mathrm{min}^{-1} \cdot \mathrm{kg}$

${ }^{\mathrm{a}} p<0.05$ vs basal values, ${ }^{\mathrm{b}} p<0.001$ vs basal values, ${ }^{\mathrm{c}} p<0.05$ vs diabetic subjects, ${ }^{\mathrm{d}} p<0.001$ vs diabetic subjects

$\mathrm{ffm}^{-1}$ per $\mathrm{pmol} / \mathrm{l}$ 

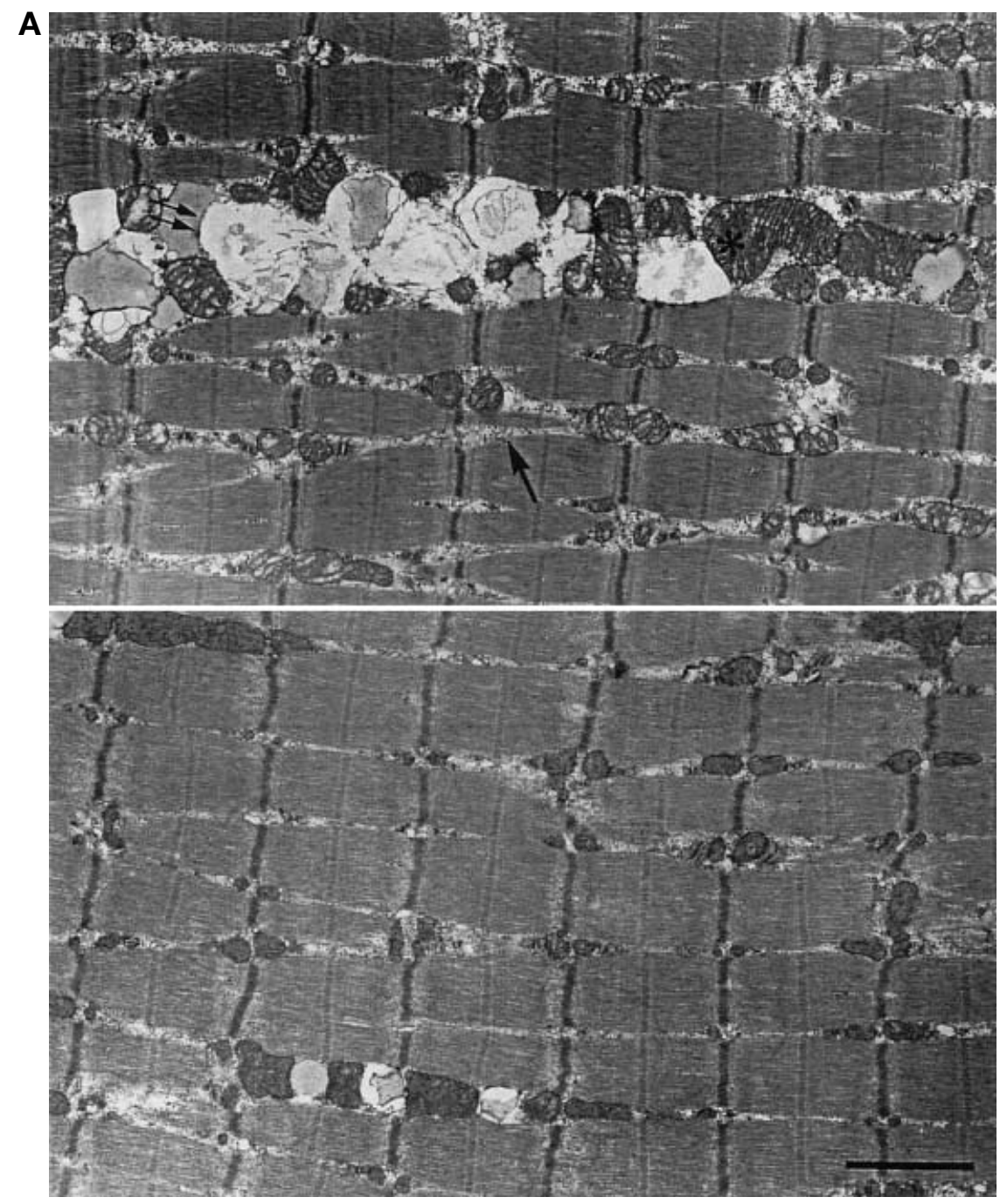

B

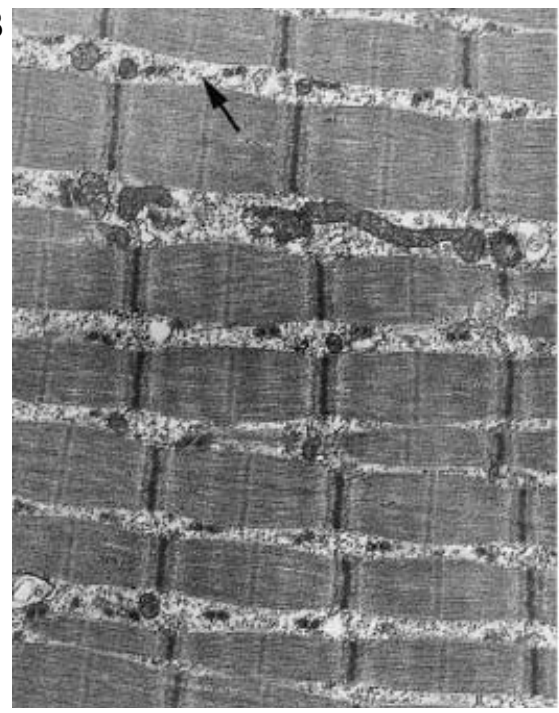

Fig. 2 A. Ultrastructure of longitudinally cut striated muscle from a Type II diabetic subject (upper) and a normoglycaemic obese subject (lower). Prominent lipid vacuoles are seen in the diabetic muscle. Mitochondria morphology in the two pictures are similar. Lipid droplets $(\rightarrow)$, mitochondria $(*)$, area

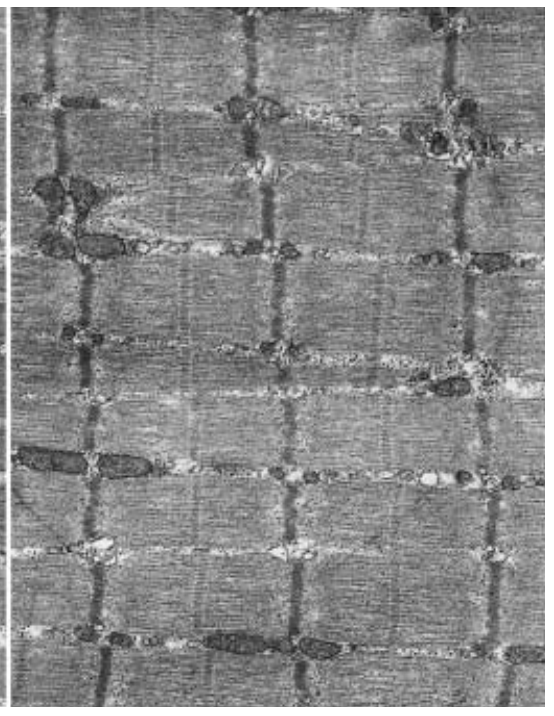

with glycogen granules $(\rightarrow), 1.5$ my-meter $(-)$. B Ultrastructure of longitudinally cut striated muscle from a Type II diabetic subject (left panel) and a normoglycaemic obese subject (right panel). Glycogen granules $(\rightarrow)$ 


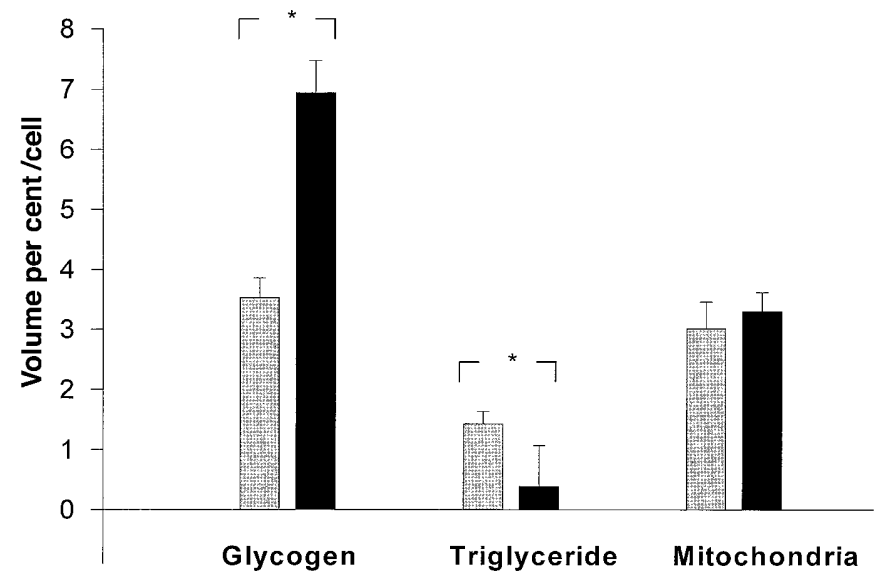

Fig. 3. Intramyocellular volume fractions of glycogen, triglyceride and mitochondria.: Diabetic cohort $(\square)$, normoglycaemic obese cohort $(\square) .{ }^{*} p<0.001$

$(3.53 \pm 0.33$ vs $6.94 \pm 0.54 \%, p<0.001)$. Mitochondria volume fraction was identical in the two groups (3.01 \pm 0.45 vs $3.30 \pm 0.32, p=$ NS), (Fig. 3$)$.

Correlation analysis showed a significant inverse relation between intramyocellular lipid content and $\mathrm{Si}_{\mathrm{Rd}}(r=-0.71, p<0.02)$ as well as $\mathrm{SI}_{\mathrm{GS}}(r=-0.6$, $p=0.05)$ in the diabetic group whereas no association could be detected in the obese normoglycaemic group $(r=-0.16, p=\mathrm{NS})$ and $(r=-0.15, p=\mathrm{NS}$, respectively). There were no significant correlations between intramyocellular lipid and BMI $(r=0.39$, $p=0.24$ and $r=0.47, p=0.15)$ and fat mass percentage $(r=0.35, p=0.3$ and $r=0.27, p=0.42)$.

In both the diabetic and obese normoglycaemic group significant positive associations were found between intramyocellular and circulating lipids, that is for fasting NEFA $(r=0.63, p=<0.05$ and $r=0.79$, $p=<0.05)$, (Fig. 4) and for TG $(r=0.74, p=0.01$ and $r=0.62, p<0.05)$.

\section{Discussion}

Patients with Type II diabetes have defects in both lipid and carbohydrate metabolism. This study clearly shows that fat accumulates intramyocellulary in big droplets of triglycerides which are located in close proximity to the mitochondria. Moreover, as previously shown in obese non-diabetic subjects [15], the extent of the intramyocellular fat accumulation was related to the degree of insulin insensitivity, in particular Rd and GS, in our obese diabetic subjects. Furthermore, by means of electron microscopy, we provide morphometric documentation for a simultaneous reduction of the amount of intramyocellular glycogen.

In this study we compared obese Type II diabetic patients with obese normoglycaemic subjects. These data are consistent with our earlier studies on insulin

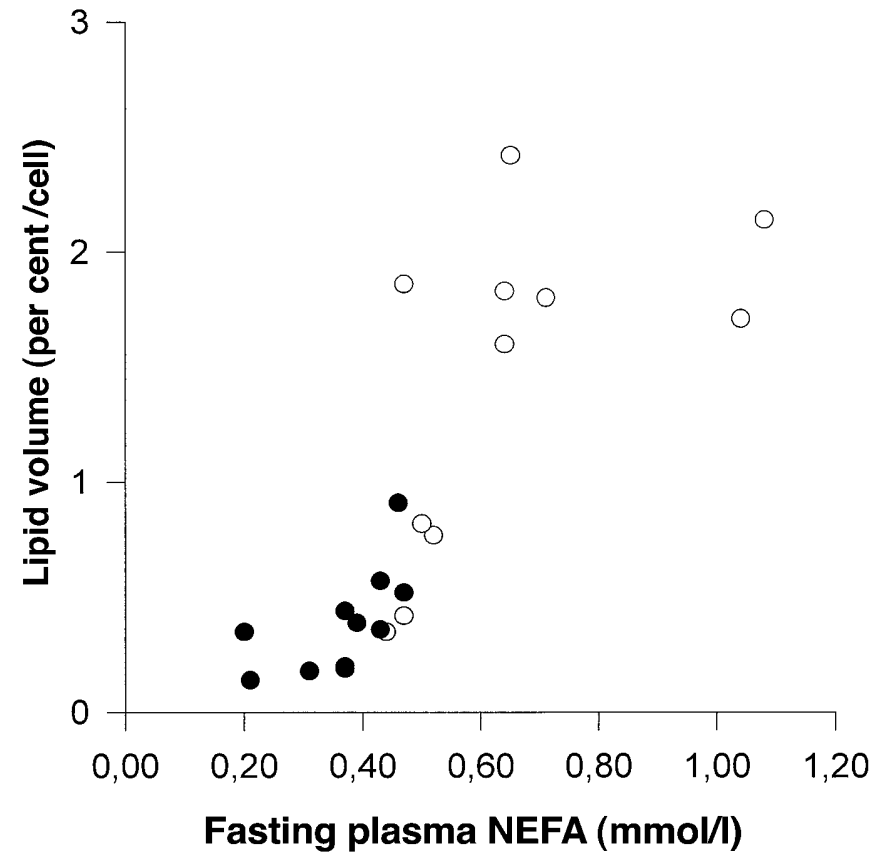

Fig. 4. Relation between fractional intramyocellular lipid volume and the fasting level of NEFA: Diabetic cohort $(\bigcirc)$, normoglycaemic obese cohort ( $)$

stimulated Rd, GS, and lipid and glucose oxidation published by our group for obese normoglycaemic and diabetic subjects [37-39] Thus, the mean glucose infusion rates during the hyperinsulinaemic euglycaemic clamp studies in the present obese normoglycaemic and Type II diabetic subjects and in the three cited studies were 8.4, 8.3 [37],11.4 [38] and 9.2 [39] and $3.1,3.6$ [37], 4.8 [38] and $5.0 \mathrm{mg} \cdot \mathrm{min}^{-1} \cdot \mathrm{kg} \mathrm{ffm}{ }^{-1}$ [39], respectively. The mean infusion rate for younger lean subjects was $12.2 \mathrm{mg} \cdot \mathrm{min}^{-1} \cdot \mathrm{kg} \mathrm{ffm}^{-1}$ [37]. However, the fasting NEFA concentrations seen in the present obese Type II diabetic and normoglycaemic subjects were somewhat lower than generally observed in similar groups. The reason for this discrepancy is not clear. A major component of the insulinresistant state noted in Type II diabetes when compared with normoglycaemic obese subjects has been attributed to a "metabolic" insulin resistance or "secondary" insulin resistance due to the various metabolic abnormalities present in the diabetic state itself, such as hyperglycaemia, hyperinsulinaemia and hyperlipidaemia, especially the increased NEFA and triglyceride concentrations $[2,40]$. This does not exclude the possibility that a component of an inherited metabolic defect could also contribute to the altered metabolic state found in obese Type II diabetic subjects [41]. Obese diabetic subjects have been shown to accumulate almost four times more triglyceride than normoglycaemic obese subjects. It is therefore possible that the excess triglyceride accumulation could be related to the diabetic state itself and/or the presence of inherited insulin resistance. This is under- 
scored by the fact that our obese normoglycaemic subjects seemed to be carrying more fat than our Type II diabetic subjects despite the close matching of BMI ratios.

The contrasting finding of a significant reduction of the glycogen content in skeletal muscle (about $50 \%$ ) is surprising given the previous biochemical estimates of glycogen concentrations in skeletal muscle $[42,43]$. It is however compatible with data on reduced glycogen synthase activity and glycogen synthesis rate in Type II diabetic patients and their relatives which in turn could be secondary to upstream defects in glucose transport and/or phosphorylation [40, 41; 44-47]. Similar reductions in intramuscular glycogen content have also demonstrated in another study on Type II diabetic subjects using the NMRtechnique which measures glycogen content in vivo [48]. More recently, using a specific biochemical extraction method using amyloglucosidase enzymatic degradation of the $\alpha-1-4$ and $\alpha-1-6$ glucosidic bonds of glycogen rather than the non-specific technique of acid hydrolysis, investigators showed a significant reduction in muscle glycogen concentration in a group of markedly insulin resistant growth hormone deficient subjects $[42,49,50]$. This discrepancy between the earlier biochemical estimations of intramuscular glycogen [42, 43] and the NMR [48] and our current data could be because the previous biochemical estimations were not sufficiently precise to establish the presence of a difference between intramuscular glycogen content in diabetic and control subjects. (We have now found intramuscular glycogen content to be significantly reduced in insulinopenic modestly hyperglycaemic diabetes in both human beings and dogs. Manuscript in preparation; Christopher, Ward, Alford et al.). Thus, the present morphometric data and the NMR findings seem to indicate that skeletal muscle glycogen content is reduced in Type II diabetes.

The biochemical explanation for increased storage of triglyceride and reduced storage of glycogen is not clear. Subjects with Type II diabetes are characterized by a compensatory hyperglycaemia and hyperinsulinaemia which could lead to normal or slightly increased skeletal muscle glucose uptake because of the mass action of hyperglycaemia itself [51]. The hyperglycaemia results in increased glucose oxidation and reduced fat oxidation across the leg (which consists mainly of skeletal muscle) in obese diabetic subjects [9]. Thus, intramyocellular glucose and NEFA are probably linked in Type II diabetes in such a way that the rate of cellular glucose processing leads to reduced skeletal muscle NEFA oxidation despite normal or increased NEFA uptake by muscles $[9,52]$. Non-esterified fatty acids are then believed to be channelled preferentially into triglyceride instead [9]. How this accumulation of triglyceride leads to insulin resistance is not known but one proposal is that increased concentrations of diacyl glycerol (DAG), following the accumulation of muscle triglyceride and long-chain acyl CoA, could lead to increased protein kinase $\mathrm{C}$ (PKC) activity with its attended suppression of the insulin action cascade by serine phosphorylation [53, 54] Alternatively, glucose transport activity and glycogen synthesis could be reduced by a direct effect of increased intramyocellular NEFA concentrations (or some NEFA metabolite) on PI-3kinase activity [55; 56]. Regardless of the exact mechanisms responsible for the fat accumulation, our data clearly shows significant inverse correlations between $\mathrm{Si}_{\mathrm{RD}}$ and $\mathrm{Si}_{\mathrm{GS}}$ and the amount of intramyocellular lipid content in skeletal muscle in Type II diabetes. These associations between intramyocellular lipid accumulation and $\mathrm{Si}_{\mathrm{RD}}$ and $\mathrm{Si}_{\mathrm{GS}}$ were not, however, evident in the obese normoglycaemic cohort. This could indicate that the intramyocellular lipid accumulation is metabolically important only in diabetic subjects, possibly because of the attended insulin resistance and decrease in activity of the insulin action cascade in muscle. Alternatively, it could indicate that the relation between $\mathrm{Si}$ and intramyocellular lipid is present in obese normoglycaemic individuals but cannot be shown because of the small range of scatter of the $\mathrm{Si}$ and/or intramyocellular lipid values. Interestingly, the relation between intramyocellular lipid and circulating lipids (NEFA and triglyceride) held for both obese normoglycaemic and obese diabetic subjects.

It could be argued that our whole body calorimetry data which showed identical basal values for lipid oxidation in the two cohorts after the overnight insulin infusion but reduced acute suppression of lipid oxidation in the Type II diabetic group during the hyperinsulinaemic phase of the clamp studies, are inconsistent with our hypothesis of reduced fat oxidation in skeletal muscle. However, a strong cautionary note needs to be added. Whole body calorimetry measurements represent a composite value for liver, adipose tissue and brain as well as skeletal muscle. As has been pointed out, it is not possible to interpolate muscle substrate utilization from whole body measurements [9].

An inverse relation between insulin sensitivity and muscle triglyceride content has previously been shown in normoglycaemic Pima Indians [15], in relatives of Type II diabetic subjects and in subjects without a family history of diabetes $[17,19,20]$. However, a NMR study [57] comparing normoglycaemic European and South Asian men suggested a role of ethnicity and/or other mechanisms for the pathogenesis of intramyocellular lipid accumulation. The authors failed to find a relation between insulin sensitivity and intramyocellular lipid in normoglycaemic South Asians, even though total intramyocellular lipid content and insulin resistance were higher in this cohort. In our study, we too did not find a relation between $\mathrm{Si}$ and intramyocellular lipid content in the obese nor- 
moglycaemic control cohort. The reason for this is not clear but, as mentioned above, could be related to sample size and/or the narrow range of intramyocellular lipid deposits in the normoglycaemic obese group or activity status of the insulin action cascade. In both the obese normoglycaemic and diabetic cohort we were able, however, to show a positive association between the intramyocellular lipid content and plasma NEFA and triglyceride which is consistent with other studies, including an NMR study which showed fasting NEFA to be an independent predictor of intramyocellular lipid [16, 17]. Moreover, the insulin-resistant relatives previously studied had higher NEFA concentrations $[19,20]$. Thus, the NMR studies and the present data, together with previous studies on pre-diabetic subjects suggest that circulating lipids do have an important role for intramyocellular lipid accumulation which in turn could contribute to the development of insulin resistance in the diabetic subjects $[3,4]$.

Another important issue is the question of accumulation of adipocytes in skeletal muscle (i.e. the extramyocellular component). Adipocytes are encountered only occasionally along the fascia and in the connective tissue of normal muscle and, in the current study, where approximately 500-2000 fibres were counted, no extramyocellular lipid component was found in any of the biopsies [36]. This contrasts with the findings using the NMR technique in which a considerable extramyocellular component has been shown in the calf muscle $[17,19]$. There is no ready explanation for this difference but it might be explained partly by the orientation-dependent features of the muscle spectrum which could have reduced the separation between extramyocellular and intramyocellular lipid. In addition, the increased volume of muscle required for NMR measurements could have led to an incorporation of extramyocellular lipid components [58]. We cannot, however, exclude the possibility that some alteration of muscle ultrastructure occurred after osmium fixation leading to a shrinkage in fibre volume or its components and a distortion of in vivo lipid deposits [32].

Increased intramyocellular volume fractions of mitochondria and triglyceride have been shown in both humans after endurance training and in animals adapted to different levels of aerobic performance [35; 59-61]. It is known that larger volumes of mitochondria and triglyceride are seen also in type 1 fibres when compared with type 2 ( $2 \mathrm{~A}$ and $2 \mathrm{~B}$ ) muscle fibres [36]. In our study, however, all subjects were characterized by a sedentary lifestyle and mitochondrial volume fractions in the two cohorts were almost identical. Furthermore, intramyocellular triglyceride content, measured by a similar stereological method in untrained young lean subjects was similar to the intramyocellular triglyceride content in our obese older normoglycaemic subjects [60]. This would argue against obesity itself directly influencing intramyocellular triglyceride content.

In summary, this study shows that Type II diabetic patients are prone to store fat intramyocellulary in skeletal muscle and that this might be associated with a simultaneous reduction in glycogen storage and enhanced insulin resistance of key skeletal muscle glucose metabolic pathways. Quantitatively, a major component of the excessive lipid content seems to be secondary in origin, related to the diabetic state itself, although a contribution from an inherited metabolic defect cannot be excluded. Our study suggests that the concentration of circulating lipid does play an important pathogenic role for intramyocellular lipid accumulation in both diabetic and obese normoglycaemic subjects.

Acknowledgements. The authors wish to express their appreciation to L. Hansen, C. Fage Olsen, K. Dyrgaard, H. Vorup, J. Tinggaard and H. Hansen at the Diabetes Research Centre and to K. Hansen at the EM-lab at the Department of Pathology for their excellent technical assistance and enthusiasm. M. Christopher, BSc, provided helpful discussion on calculations of insulin sensitivities of glucose pathways. This study was supported by grants from the Institute of Clinical Research Odense University Hospital, the Danish Diabetes Association and the Novo Nordisk Foundation.

\section{References}

1. Reaven GM (1988) Role of insulin resistance in human disease. Banting lecture. Diabetes 37: 1595-1607

2. Frayn KN, Williams CM, Arner P (1996) Are increased plasma non-esterified fatty acid concentrations a risk marker for coronary heart disease and other chronic diseases? Clin Sci (Colch) 90: 243-253

3. Paolisso G, Tataranni PA, Foley JE, Bogardus C, Howard BV, Ravussin E (1995) A high concentration of fasting plasma non-esterified fatty acids is a risk factor for the development of NIDDM. Diabetologia 38: 1213-1217

4. Perseghin G, Ghosh S, Gerow K, Shulman GI (1997) Metabolic defects in lean nondiabetic offspring of NIDDM parents: a cross-sectional study. Diabetes 46: 1001-1009

5. McGarry JD (1992) What if Minkowski had been ageusic? An alternative angle on diabetes. Science 258: 766-770

6. Randle PJ, Garland PJ, Hales CN, Newsholme (1963) The glucose fatty-acid cycle. Its role in insulin sensitivity and the metabolic disturbances of diabetes mellitus. Lancet 785-789

7. Boden G, Jadali F (1991) Effects of lipid on basal carbohydrate metabolism in normal men. Diabetes 40: 686-692

8. Felley CP, Felley EM, van MG, Frascarolo P, Jequier E, Felber JP (1989) Impairment of glucose disposal by infusion of triglycerides in humans: role of glycemia. Am J Physiol 256: E747-E752

9. Kelley DE, Simoneau JA (1994) Impaired free fatty acid utilization by skeletal muscle in non-insulin-dependent diabetes mellitus. J Clin Invest 94: 2349-2356

10. Vaag A, Skott P, Damsbo P, Gall MA, Richter EA, Beck Nielsen H (1991) Effect of the antilipolytic nicotinic acid analogue acipimox on whole-body and skeletal muscle glu- 
cose metabolism in patients with non-insulin-dependent diabetes mellitus. J Clin Invest 88: 1282-1290

11. Oakes ND, Kennedy CJ, Jenkins AB, Laybutt DR, Chisholm DJ, Kraegen EW (1994) A new antidiabetic agent, BRL 49653, reduces lipid availability and improves insulin action and glucoregulation in the rat. Diabetes 43: 1203-1210

12. Levin K, Thye-Roenn P, Foot E, Beck-Nielsen H (1997) Metabolic effects of troglitazone in NIDDM patients. Endocrinol Metab 4: 255-264

13. Li M, Bjorntorp P (1995) Triglyceride uptake in muscles in rats. Obes Res 3: 419-426

14. Jensen MD, Haymond MW, Rizza RA, Cryer PE, Miles JM (1989) Influence of body fat distribution on free fatty acid metabolism in obesity. J Clin Invest 83: 1168-1173

15. Pan DA, Lillioja S, Kriketos AD et al. (1997) Skeletal muscle triglyceride levels are inversely related to insulin action. Diabetes 46: 983-988

16. Phillips DI, Caddy S, Ilic V et al. (1996) Intramuscular triglyceride and muscle insulin sensitivity: evidence for a relationship in nondiabetic subjects. Metabolism 45: 947-950

17. Krssak M, Falk PK, Dresner A et al. (1999) Intramyocellular lipid concentrations are correlated with insulin sensitivity in humans: a $1 \mathrm{H} \mathrm{NMR} \mathrm{spectroscopy} \mathrm{study.} \mathrm{Diabetologia}$ 42: $113-116$

18. Stein DT, Szczepanik L, Dobbins R, Mcgarry JD (1999) Increasing intramyocellular triglyceride stores are associated with impaired glucose tolerance and NIDDM. Diabetes 48[Suppl.1]:1254A (Abstract)

19. Jacob S, Machann J, Rett K et al. (1999) Association of increased intramyocellular lipid content with insulin resistance in lean nondiabetic offspring of type 2 diabetic subjects. Diabetes 48: 1113-1119

20. Perseghin G, Scifo P, De Cobelli F et al. (1999) Intramyocellular triglyceride content is a determinant of in vivo insulin resistance in humans: a $1 \mathrm{H}-13 \mathrm{C}$ nuclear magnetic resonance spectroscopy assessment in offspring of type 2 diabetic parents. Diabetes 48: 1600-1606

21. McGuire EA, Helderman JH, Tobin JD, Andres R, Berman M (1976) Effects of arterial versus venous sampling on analysis of glucose kinetics in man. J Appl Physiol 41: 565-573

22. Hother-Nielsen O, Henriksen JE, Staehr P, Beck-Nielsen H (1995) Labelled glucose infusate technique in clamp studies. Is precise matching of glucose specific activity important? Endocrinol Metab 2: 275-287

23. Frayn KN (1983) Calculation of substrate oxidation rates in vivo from gaseous exchange. J Appl Physiol 55: 628-634

24. Tappy L, Owen OE, Boden G (1988) Effect of hyperinsulinemia on urea pool size and substrate oxidation rates. Diabetes 37: 1212-1216

25. Steele R (1959) Influence of glucose loading and of injected insulin on hepatic glucose output. Ann NY Acad Sci 82: 420-430

26. Christopher MJ, Rantzau C, Ward GM, Alford FP (1994) Impact of variable insulinemia and glycemia on in vivo glycolysis and glucose storage in dogs. Am J Physiol 266: E62E71

27. Rossetti L, Lee YT, Ruiz J, Aldridge SC, Shamoon H, Boden G (1993) Quantitation of glycolysis and skeletal muscle glycogen synthesis in humans. Am J Physiol 265: E761E769

28. Bergman RN, Finegood DT, Ader M (1985) Assessment of insulin sensitivity in vivo. Endocr Rev 6: 45-86

29. Christopher MJ, Rantzau C, Ward GM, Alford FP (1995) Insulinopenia and hyperglycemia influence the in vivo partitioning of GE and SI. Am J Physiol 268: E410-E421
30. Lukaski HC, Johnson PE, Bolonchuk WW, Lykken GI (1985) Assessment of fat-free mass using bioelectrical impedance measurements of the human body. Am J Clin Nutr 41: 810-817

31. Kelley DE, Mokan M, Mandarino LJ (1992) Intracellular defects in glucose metabolism in obese patients with NIDDM. Diabetes 41: 698-706

32. Weibel ER (1979) Stereological Methods, Practical Methods for Biological Morphometry, Vol 1, Academic Press, London

33. Gundersen HJ, Bendtsen TF, Korbo L et al. (1988) Some new, simple and efficient stereological methods and their use in pathological research and diagnosis. APMIS 96: 379-394

34. Toivonen E, Hemmila I, Marniemi J, Jorgensen PN, Zeuthen J, Lovgren T (1986) Two-site time-resolved immunofluorometric assay of human insulin. Clin Chem 32: 637-640

35. Taylor CR, Weibel ER, Weber JM et al. (1996) Design of the oxygen and substrate pathways. I. Model and strategy to test symmorphosis in a network structure. J Exp Biol 199: $1643-1649$

36. Carpenter S, Karpati G (1984) Pathology of Skeletal Muscle, Churchill Livingstone, New York

37. Hother-Nielsen O, Beck-Nielsen H (1991) Insulin resistance, but normal basal rates of glucose production in patients with newly diagnosed mild diabetes mellitus. Acta Endocrinol (Copenh) 124: 637-645

38. Vaag A, Alford F, Henriksen FL, Christopher M, Beck Nielsen H (1995) Multiple defects of both hepatic and peripheral intracellular glucose processing contribute to the hyperglycaemia of NIDDM. Diabetologia 38: 326-336

39. Staehr P, Hother-Nielsen O, Levin K, Juul Holst J, BeckNielsen H (2001) Assessment of Hepatic Insulin Action in Obese Type 2 Diabetic patients. Diabetes (In press)

40. Damsbo P, Vaag A, Hother Nielsen O, Beck Nielsen H (1991) Reduced glycogen synthase activity in skeletal muscle from obese patients with and without Type II (non-insulin-dependent) diabetes mellitus. Diabetologia 34: 239-245

41. Vaag A, Henriksen JE, Beck Nielsen H (1992) Decreased insulin activation of glycogen synthase in skeletal muscles in young nonobese Caucasian first-degree relatives of patients with non-insulin-dependent diabetes mellitus. J Clin Invest 89: 782-788

42. Vaag A, Damsbo P, Hother NO, Beck NH (1992) Hyperglycaemia compensates for the defects in insulin-mediated glucose metabolism and in the activation of glycogen synthase in the skeletal muscle of patients with type 2 (non-insulin-dependent) diabetes mellitus. Diabetologia 35: 80-88

43. Martin IK, Katz A, Wahren J (1995) Splanchnic and muscle metabolism during exercise in NIDDM patients. Am J Physiol 269: E583-E590

44. Bogardus C, Lillioja S, Stone K, Mott D (1984) Correlation between muscle glycogen synthase activity and in vivo insulin action in man. J Clin Invest 73: 1185-1190

45. Rothman DL, Shulman RG, Shulman GI (1992) 31P nuclear magnetic resonance measurements of muscle glucose-6phosphate. Evidence for reduced insulin-dependent muscle glucose transport or phosphorylation activity in non-insulin-dependent diabetes mellitus. J Clin Invest 89: 1069-1075

46. Bjornholm M, Kawano Y, Lehtihet M, Zierath JR (1997) Insulin receptor substrate-1 phosphorylation and phosphatidylinositol 3-kinase activity in skeletal muscle from NIDDM subjects after in vivo insulin stimulation. Diabetes 46: $524-527$ 
47. Lawrence-JC, Roach PJ (1997) New insights into the role and mechanism of glycogen synthase activation by insulin. Diabetes 46: 541-547

48. Shulman GI, Rothman DL, Jue T, Stein P, DeFronzo RA, Shulman RG (1990) Quantitation of muscle glycogen synthesis in normal subjects and subjects with non-insulin-dependent diabetes by $13 \mathrm{C}$ nuclear magnetic resonance spectroscopy [see comments]. N Engl J Med 322: 223-228

49. Keppler D (1984) Glycogen. In: Bergmeyer HU (ed) Methods of enzymatic analysis. Decker K. vol 6, Verlag Chemie Weinheim, pp11-17

50. Christopher M, Hew FL, Oakley M, Rantzau C, Alford F (1998) Defects of insulin action and skeletal muscle glucose metabolism in growth hormone-deficient adults persist after 24 months of recombinant human growth hormone therapy. J Clin Endocrinol Metab 83: 1668-1681

51. Mandarino LJ, Consoli A, Jain A, Kelley DE (1993) Differential regulation of intracellular glucose metabolism by glucose and insulin in human muscle. Am J Physiol 265: E898-E905

52. Sidossis LS, Stuart CA, Shulman GI, Lopaschuk GD, Wolfe RR (1996) Glucose plus insulin regulate fat oxidation by controlling the rate of fatty acid entry into the mitochondria. J Clin Invest 98: 2244-2250

53. Griffin ME, Marcucci MJ, Cline GW et al. (1999) Free fatty acid-induced insulin resistance is associated with activation of protein kinase $\mathrm{C}$ theta and alterations in the insulin signaling cascade. Diabetes 48: 1270-1274
54. Schmitz PC, Oakes ND, Browne CL, Kraegen EW, Biden TJ (1997) Reversal of chronic alterations of skeletal muscle protein kinase C from fat-fed rats by BRL-49653. Am J Physiol 273: E915-E921

55. Roden M, Price TB, Perseghin G et al. (1996) Mechanism of free fatty acid-induced insulin resistance in humans. J Clin Invest 97: 2859-2865

56. Dresner A, Laurent D, Marcucci M et al. (1999) Effects of free fatty acids on glucose transport and IRS-1-associated phosphatidylinositol 3-kinase activity. J Clin Invest 103: 253-259

57. Forouhi NG, Jenkinson G, Thomas EL et al. (1999) Relation of triglyceride stores in skeletal muscle cells to central obesity and insulin sensitivity in European and South Asian men. Diabetologia 42: 932-935

58. Boesch C, Slotboom J, Hoppeler H, Kreis R (1997) In vivo determination of intra-myocellular lipids in human muscle by means of localized 1H-MR-spectroscopy. Magn Reson Med 37: 484-493

59. Hurley BF, Nemeth PM, Martin WH, Hagberg JM, Dalsky GP, Holloszy JO (1986) Muscle triglyceride utilization during exercise: effect of training. J Appl Physiol 60: 562-567

60. Hoppeler H, Howald H, Conley K et al. (1985) Endurance training in humans: aerobic capacity and structure of skeletal muscle. J Appl Physiol 59: 320-327

61. Vock R, Hoppeler H, Claassen H et al. (1996) Design of the oxygen and substrate pathways. VI. structural basis of intracellular substrate supply to mitochondria in muscle cells. J Exp Biol 199: 1689-1697 